\title{
Pensar la autonomía puigiana en tiempo de un orden mundial en transición ${ }^{1}$
}

Think of the autonomy of Puig in time of a world order in transition

ALEJANDRO SIMONOFF Investigador del Instituto de Relaciones Internacionales (IRI) y del Instituto de Investigaciones en Humanidades y Ciencias Sociales (IdIHCS), Universidad Nacional de La Plata. Correo electrónico: asimonoff2010@gmail.com

\section{Resumen}

Juan Carlos Puig pensó la factibilidad de márgenes de maniobra en un entorno internacional relativamente estable.

Sin embargo, desde el fin de la guerra fría, venimos observando la falta de conformación de un orden mundial y cómo éste afecta a todos los países, y en particular para el caso de Argentina.

Por ello a partir de esa situación y teniendo en cuentan los lineamientos que este pensador del Cono Sur dio al concepto de autonomía, nos proponemos hacer una lectura de ellos, para establecer algunos parámetros de certitud en nuestro análisis.

\section{Palabras Clave}

Autonomía - Teoría de las Relaciones Internacionales - Política Exterior

\section{Abstract}

Juan Carlos Puig thought the feasibility of margins of maneuver in a relatively stable international environment. However, since the end of the cold war, we have been observing the lack of conformation of a world order and how it affects all countries, and in particular in the case of Argentina.

Therefore, starting from this situation and considering the guidelines that these thinkers of the Southern Cone gave the concept of autonomy, we propose to make a reading of them, to establish some parameters of certainty in our analysis.

\section{Keywords}

Autonomy - Theory of International Relations - Foreign Policy

\footnotetext{
${ }^{1}$ Este artículo es una revisión de: Pensar la autonomía en el Cono Sur en tiempo de transición del Orden Mundial presentado en el XXXI Congreso ALAS - Montevideo 2017.
} 
Perspectivas Revista de Ciencias Sociales - ISSN 2525-1112|Año 3 No. 6 Julio-Diciembre 2018, pp. 221-242

\section{Pensar la autonomía puigiana en tiempo de un orden mundial en transición}

Juan Carlos Puig pensó la factibilidad de los márgenes de maniobra en un entorno internacional relativamente estable. Sin embargo, desde el fin de la Guerra Fría, venimos observando la falta de conformación de un Orden mundial y cómo ello afecta a todos los países y, en particular, al caso de Argentina.

Nuestro objetivo en este trabajo será pensar a la autonomía como un instrumento de inserción internacional, por ello recabaremos a partir del caso argentino, cuáles son los elementos que conforman el sistema internacional y nos preguntaremos si dichos aspectos visualizados son útiles para acceder a un escenario de transición como el actual.

\section{Los elementos del sistema internacional en clave puigiana}

El análisis de los elementos que conforman el sistema internacional en la concepción puigiana resulta imprescindible para poder comprender la existencia de márgenes de maniobra en tanto instrumento de inserción internacional.

Como hemos señalado en otros trabajos, el pensamiento autonómico fue objeto de críticas desde los años ochenta por parte de ciertas nuevas escuelas de relaciones internacionales argentinas (neoconservadora, neoliberal y socio-histórica) (Simonoff, 2012) que podemos resumir y ejemplificar con la siguiente afirmación de Roberto Russell y Juan Gabriel Tokatlián: “ (...) la globalización, la interdependencia, los problemas de naturaleza trasnacional no dejan espacio para concebir a la autonomía en clave de oposición a otros o de aislacionismo del exterior, tal como se hizo en el pasado"2 (Russell y Tokatlián, 2010, 14).

Juan Carlos Puig no desconocía las transformaciones que estaban aconteciendo en el sistema internacional desde los años sesenta, ni tampoco propuso una autonomía en esos términos -como sinónimo de confrontación-, sino como "la máxima capacidad de decisión propia que se puede tener, teniendo en cuenta los condicionamientos objetivos del mundo real (...)" (Puig, 1980, 149)

Con respecto a la falta de actualidad del autonomismo clásico queremos señalar que Puig y Helio Jaguaribe entienden a la Guerra Fría en dos planos: (1) "entre las superpotencias" que determinan el sistema internacional por su oscilación entre fases de cooperación y de conflicto; (2) en "la centro-periferia" que existe en todos sistemas imperiales; si bien se pueden hacer diferencias de acuerdo a cada periodo histórico (Jaguaribe, 1979, 94) ${ }^{3}$. Si acordamos con ello, los sucesos acaecidos a fines de los años ochenta y principios de los noventa, terminaron con el primero de ellos, el conflicto Este-Oeste, pero de ningún modo con el Norte-Sur. La predominancia de este último fue muy bien resaltada por Raúl Bernal Meza:

\footnotetext{
${ }^{2}$ La cursiva es propia.

${ }^{3}$ Si bien ambos autores fueron caracterizados como realistas de fines y no de medios (Dallanegra, 2009), creemos que hay que leerlos dentro de las lecturas críticas de las Relaciones Internacionales con las que están fuertemente emparentados.
} 
“(..) 'los lazos de dominación-dependencia' se han modificado en su ethos -en su apariencia-, bajo las lógicas que impone la dominación sobre las estructuras internacionales (incluyendo el control de los organismos internacionales, Consejo de Seguridad, Fondo Monetario Internacional- FMI-, Organización Mundial de Comercio -OMC-, etc.) y de la (casi) absoluta primacía científico-tecnológica; pero, a través de estas mismas lógicas, esos lazos 'se han profundizado' (...)" $(2013,50)$

Es decir, la confrontación asimétrica Norte-Sur tiene una mayor visibilidad en la actualidad que en el escenario internacional anterior.

\section{La división de funciones del régimen internacional}

El funcionamiento del régimen internacional -"y como cualquier grupo humano -macro o micro"- posee una división de funciones - "y criterios supremos de reparto, impuestos, aceptados o surgidos espontáneamente- que rige las conductas de quienes integran el grupo, en este caso, la comunidad internacional." (Puig, 1986, 54) 4 El primero de esos elementos, la división de funciones, llevó a este autor, tomando de Werner Goldschmidt, a caracterizar a los actores internacionales en tres grupos: los primeros, los "repartidores supremos", son los gobernantes de las superpotencias mundiales y quienes toman decisiones y supervisan su cumplimiento; los "repartidores" son los mandatarios de los demás Estados, que ejecutan esas decisiones; y finalmente, el resto de los habitantes del mundo, son los "recipendiarios", los que obedecen. (Puig, 1980, 141)

Asimismo, el Estado como actor internacional no es percibido como uno único y racional, sino como la exteriorización de los intereses de los grupos de presión o las elites que se disputan su control. La variedad de opciones son recogidas por diversas categorías que se definen por el rol que le asignan las elites a su proyecto de Estado en el Sistema Internacional, ya sea por no poseer un proyecto propio y, por lo tanto, estar plegado a la gran potencia (dependencia paracolonial), por poseer uno, aunque sea dependiente (dependencia racionalizada) o si tiene uno autonomista (autonomista heterodoxo), o si plantea uno que lleve a una ruptura estratégica (autonomía secesionista). (Puig, 1984)

Por otra parte, en este análisis el Estado no tiene la exclusividad en el sistema. Ello se plantea por la presencia de organismos internacionales de origen intergubernamental (IGOS), las empresas transnacionales (BINGOS), y ONGs, entre otros actores, los cuales "operan a nivel regional, continental o mundial y, por la índole de sus actividades, atraviesan sutil o abiertamente, las mismas fronteras nacionales." (Puig, 1970, 33) En efecto, los cambios que están aconteciendo a nivel mundial fueron observados de manera temprana en los años setenta, cuando sostuvo que la

\footnotetext{
${ }^{4}$ Sin embargo, Puig era consciente de la dificultad de asimilar el sistema nacional al internacional: en su crítica a Morton Kaplan señaló que el segundo "no constituye un sistema político en stricto sensu, porque no existen gobernantes internacionales genuinos y, por tanto, como diría Kelsen, las funciones jurídicas en la comunidad internacional se llevan a cabo descentralizadamente por los mismos gobernantes de los Estados." (Puig en Laviña y Baldomir, 1983, 271)
} 
"acelerada transformación ha puesto de manifiesto la absoluta incompatibilidad de las nuevas condiciones de vida con la estructura del Mundo surgido históricamente al desintegrarse la Edad Media." (Puig, 1970, 32) Esta tensión repercute en la agenda de seguridad internacional, que resulta más complicada para los países periféricos ya que mientras las grandes potencias "son Estados regiones o Estados continentes por sí mismos o en asociación con otros y pueden aspirar a desempeñar un papel protagónico, orientador o simplemente mediador en las relaciones mundiales", los pequeños y medianos se encuentran lejos de una "solución satisfactoria" para ello. (Puig, 1970, 32)

\section{Los criterios del régimen internacional}

Otro elemento destacado es el funcionamiento de la anarquía, donde Puig se diferencia del realismo clásico y se acerca a Stephen Waltz (1988) ya que identifica una serie de elementos que determinan su funcionamiento por la existencia de una división de tareas y de criterios que ordenarían al Régimen Internacional, limitando y conformando a la anarquía de un modo más preciso que el pensamiento morgenthauniano. Es decir, el régimen internacional se articula según ciertos elementos que delimitarían el estado de naturaleza y que exceden la vigencia del modelo bipolar: "(...) El hecho es que a nivel internacional países capitalistas y socialistas, desarrollados o en vías de desarrollo, aceptan determinados regímenes de valores, de participación, de poder y de propiedad". (Puig, 1980, 143) La anarquía del sistema internacional, aunque permanente, no resulta transhistórica como en el realismo clásico, sino una particular forma influenciada por el contexto, caracterizada no sólo como ausencia de gobierno mundial, sino también como un elemento que sostiene y erosiona determinada jerarquía.

Los criterios del régimen internacional que limitan la anarquía en la visión de Puig son: la posesión de armas de destrucción masiva, la impermeabilidad interbloque, la autonomización intrabloque, la ruptura estratégica, la permeabilidad extrabloque y la prohibición del uso de la fuerza para las potencias medianas y pequeñas. El primero de ellos, "la posesión de armas de destrucción masiva", es "un criterio supremo de reparto de carácter dinámico", ya que le garantizaba, al promover tratados de desnuclearización, una "forma de gobierno" del mundo bipolar. (Puig, 1984, I, 55) Inicialmente fue impuesto por los repartidores supremos de las superpotencias,

“(...) pero posteriormente fue aceptado por una inmensa mayoría de repartidores supremos nacionales, en virtud del Tratado Sobre no proliferación de Armas Nucleares que entró en vigencia el 5 de marzo de 1979. Como es sabido, según este Tratado se prohíbe a los Estados nucleares la transferencia de armamento nuclear o de otros artefactos explosivos nucleares o del control sobre ellos, a los no nucleares, recibir o fabricar ese tipo de armamento (...)" (Puig, 1984, I, 55) 
Perspectivas Revista de Ciencias Sociales - ISSN 2525-1112|Año 3 No. 6 Julio-Diciembre 2018, pp. 221-242

Es decir que la posesión por algunos Estados y la promoción de la no proliferación para otros (los medianos y pequeños), es el criterio angular del régimen internacional.

El segundo de ellos, "la impermeabilidad interbloque" se sustentó en el acuerdo de Yalta: "(...) cada una de las potencias comandaría un bloque, y que los bloques serían impermeables (...), no estarían sometidos a la posibilidad de injerencias externas, tanto del otro bloque cuanto del organismo mundial de seguridad (...)" (Puig, 1984, I, 69). Las potencias harían lo que fuera necesario para sustentar este carácter, por caso una acción contra el otro bloque en defensa del principio de no intervención. ${ }^{5}$ Pero este criterio no impidió la asistencia a sus Estados alineados, lo que llevó a estos últimos a una "automonización progresiva", o a la ruptura estratégica. En prueba de ello, afirma Puig:

"Los supremos repartidores nacionales deberían ajustarse en sus decisiones internacionales a este espacio; en tal caso, su margen "actual" de decisión autónoma coincidiría con el "potencial". Pueden muy bien quedarse rezagados con respecto a la real capacidad autonómica (y es lo que ocurre en la mayoría de las situaciones) por error de apreciación o, lo que es peor, por intereses creados". (1984, I, 72)

Es decir, el proceso de construcción de la autonomía en tanto "ampliar el 225 margen de decisión propia" (Puig, 1986: 51), depende de las condiciones objetivas (el "potencial"), como de la acción frente a ella. Ese proceso se constituye en la lectura puigiana del siguiente modo:

“(...) el logro de una mayor autonomía supone un juego estratégico previo de suma cero, en el cual alguien gana lo que otro pierde... la maniobra estratégica que éste [el antiguo cliente] debe poner en movimiento sólo será exitosa en la medida en que el diagnóstico político referido al adversario [la potencia dominante] sea correcto y, como consecuencia, movilice recursos de poder que sean suficientes para dominar la voluntad del oponente". (Puig, 1984: I: 79)

Por este hecho, un proceso de suma cero, la construcción de márgenes de maniobra fue interpretada por algunos autores, como Carlos Escudé, Roberto Russell y Juan Gabriel Tokatlián, entre otros, en clave de "oposición", como rechazo, pero en realidad Puig la percibió en términos dialécticos, en la relación con el Bloque; y realizada en la categoría denominada "Autonomía Heterodoxa", una de las cuatro categorías establecidas por Juan Carlos Puig. Este proceso de autonomización: "(...) solo puede producirse en la medida en que los países avanzan en materia de propia

\footnotetext{
${ }^{5}$ Nótese la semejanza de esta característica, con el criterio de "doble cárcel" del a Guerra Fría hecha por las perspectivas críticas. (Halliday, 2002)
} 
viabilidad, lo cual supone no solo recursos suficientes mínimos (Helio Jaguaribe), sino también, y sobre todo, elites funcionales, o sea decidida a emprender el camino de la automatización (...)" (Puig, 1980, 154)

La viabilidad nacional es uno de los dos registros para el logro de autonomía según Helio Jaguaribe ${ }^{6}$, que "es esencialmente histórica y relativa" y se determina por "la relación existente entre los recursos humanos y naturales de que dispone una nación en un momento dado y el nivel de la tecnología existente en ese momento." (Jaguaribe, 1973: 113)

Las diferencias entre ambos estudiosos, están en el hecho que Puig distinguió, siguiendo a Donald Puchala, dos formas de poder, uno al que denomina "Poder Nacional Bruto" (que está conformado por todos los recursos materiales que dispone un Estado o sociedad) y el "Poder Externamente Proyectable", "que comprende el total de recursos de que puede disponer el Gobierno para la obtención de objetivos de política exterior." (Puig, 1980, 134) En otras palabras, la construcción de capacidades está determinada por la existencia de bases materiales y de la voluntad para ejercerla.

Cuando los autores analizan solo los recursos materiales, se cristaliza el predominio absoluto de las grandes potencias y la condena de los Estados pequeños y medianos "a un periferismo permanente." (Puig en Laviña y Baldomir, 1983, 271) Para Juan Carlos Puig: (...) el hilo conductor es el de la autonomía que puede tener diversos grados, y cuya tipificación es imprescindible, como ha demostrado en diversos estadios, para diseñar políticas y estrategias congruentes con el margen de la autonomía potencial que tienen los Estados (...)" (Puig, 1983, IX) Por ese motivo, nuestro autor establece esos diversos grados a través de un continuum dependenciaautonomía que se expresan en sus categorías de inserción ya mencionadas: dependencia para-colonial, dependencia racionalizada, autonomía heterodoxa y autonomía secesionista.

La primera de ellas, la "dependencia para-colonial", es el modelo en el cual "(...) el Estado posee formalmente un gobierno soberano y no es una colonia, pero en realidad los grupos que detentan el poder efectivo en la sociedad nacional no constituyen otra cosa que un apéndice del aparato gubernativo y de la estructura del poder real de otro Estado." (Puig, 1984: I: 74) La segunda, la "dependencia nacional", es aquella donde "los grupos que detentan el poder real racionalizan la dependencia $y$, por tanto, se fijan fines propios que pueden llegar a conformar un proyecto nacional compartido globalmente en sus rasgos esenciales." (Puig, 1984: I: 74). La existencia de un proyecto nacional marcó la diferencia con el modelo de dependencia paracolonial, ya que "se impusieron algunos límites a la influencia, en principio determinante, de la potencia imperial." (Puig, 1984: I: 75). Como ejemplo de ello, Puig destaca las doctrinas Calvo, Tejedor y Drago en donde el país enfrentó la pretensión de las potencias europeas de imponer principios como el de extraterritorialidad o el cobro compulsivo de deudas. (Puig, 1984). La diferencia entre ambas está en que: “(...) es útil distinguir entre una situación caracterizada porque el aparato gubernativo

${ }^{6}$ El otro es la permisividad internacional. 
formal y los grupos que ostentan el poder real (los repartidores supremos en la orbital nacional) se sienten parte del régimen metropolitano, y otra en que la dependencia se encuentra racionalizada". (Puig, 1984: 57)

La tercera categoría, la "autonomía heterodoxa" se realiza a través de la aceptación de la conducción estratégica del bloque, aunque existen tres aspectos que lo diferencian del anterior: a) el modelo de desarrollo interno puede no coincidir con las expectativas de la metrópoli; b) en que las relaciones internacionales del país periférico no sean globalmente estratégicas; y, c) separa el interés nacional de la potencia dominante y el interés estratégico del bloque. (Puig, 1984: I: 78)

A pesar que la autonomía en Puig se produce por "un juego estratégico previo de suma cero" (Puig, 1984: I: 79), no hay confrontación, ni desafío en los temas cruciales para la/las potencia/s: “(...) La vocación autonómica de tipo heterodoxo supone que existe una aceptación del liderato de la o las Potencias dominantes y que, en cuestiones realmente cruciales, los periféricos optaran por responder a las aspiraciones del centro (...)" (Puig, 1980: 152) Con respecto a este aspecto señalaremos dos cosas más: la primera, es que la existencia de niveles de conflictividad entre un Estado central y otro periférico, no deben ser despejados sin un criterio ordenador; la acción de estos últimos debe estar guiada por una "estrategia adecuada para implementar" la autonomía heterodoxa, "donde el punto de vista de un Estado periférico y dependiente, es el de conocer con razonable exactitud el punto crucial en que los intereses cotidianos se convierten en vitales..." (Puig, 1980: 153) En segundo lugar, “ (...) si bien es cierto que la autonomía no garantiza por sí misma que quien goza de ella vaya a tomar decisiones acertadas, de la misma manera 'no todas las políticas impuestas por el dominante tienen que ser necesariamente perjudiciales para el subordinado"'7 (...) (, Puig, 1986: 40) La confrontación reducida, no excluye la colaboración con la gran potencia pero tampoco su implementación es garantía de éxito. Además, esta confrontación principal, no supone un uso extensivo de ella a otras relaciones, y lo mismo ocurre con la integración ya que para nuestro autor "la integración en sí misma tampoco es autonomizante. En el fondo, es instrumental y su sentido dependerá del objetivo que se fije." (Puig, 1980, 154) ${ }^{8} \mathrm{Al}$ respecto, Puig identifica tres características principales: es un fenómeno social; "no solo implica a los Estados sino también a cualquier agrupación, micro (como sociedades y empresas) y macro, la comunidad internacional", y tiene "como propósito lograr que los grupos sociales en cuestión renuncien en determinadas materias a la actuación individual para hacerlo en forma conjunta y con sentido de pertenencia." (Puig, 1986, 41). Cabe destacar que, a diferencia de lo que le asignan sus críticos, nuestro autor no limita la acción de la integración a los Estado Nación, ni a las cúpulas que los dirigen, o las elites funcionales al proyecto autonómico, sino que

\footnotetext{
${ }^{7}$ Los apóstrofes son propios.

${ }^{8}$ En su texto de 1985 la integración solidarista adquiere en el discurso puigiano una condición central para el logro de autonomía, es decir a medida que se debilitaba el rol del Estado Nación en el contexto internacional, ese tipo de aparcería asume un rol más relevante. (Puig, 1986)
} 
también debe ser producto de las sociedades que buscan la aparcería. ${ }^{9}$ En este aspecto prefigura muchos de los análisis que ocurrieron en los años noventa, donde la sociedad civil es visibilizada por los analistas.

El desafío de la integración está en que, las sociedades latinoamericanas donde conviven un nacionalismo estatal y otro regional -pero que no son "comparables en intensidad"-, trabajen del siguiente modo: "(...) El transcurso del Estado-Nación al Estado-región es justamente eso, un transcurso, en que, al principio, naturalmente, el nacionalismo del Estado Nación (valga la redundancia) ocupa prácticamente toda la escena y el nacionalismo regional, es sólo embrionario". (Puig, 1981, 111-112)

El desarrollo de un nacionalismo regional, en convivencia con otro del EstadoNación, resulta central para la construcción de una propuesta integracionista, e incluso más allá de las elites que lo impulsan. La comunidad de valores y acción son producto para Puig de una lectura política hecha por las elites que las engloba, pero la decisión de integrarse no resulta suficiente, ya que el éxito o su fracaso depende de la percepción que las sociedades involucradas tengan de las ganancias o pérdidas que esta otorgue, no sólo producto de una ideología de la integración. (Puig, 1978, 94) Es decir, en la lectura puigiana la integración necesita, tanto del desarrollo de un nacionalismo regional en el plano de las elites, pero también en la sociedad civil, como de decisiones políticas acertadas y de cómo evolucionan sus evaluaciones del proceso para el logro de la asociación. (Puig, 1978, 95)

Para Puig, el proceso de la integración es también una condición, aunque debe ser reforzado por quien lo impulsa. No es un fenómeno univoco, existe bajo dos formas: una comercialista y otra solidaria. Entre ambas existen marcadas diferencias: la primera lleva a reforzar el régimen internacional vigente y a profundizar las asimetrías (inevitables) entre los socios al adoptar una perspectiva exclusivamente económica e interdependiente. Así, la integración comercialista, es la que impulsó la CEPAL, y según su lectura fracasó porque no trató de modificar, siquiera evolutivamente, el régimen internacional, que era el verdadero productor de la injusticia. (Puig, 1981: 135-136) ${ }^{10}$

El segundo problema que observa Puig en este tipo de asociación para nuestra región no sólo es la importancia del sistema mundial, sino también el rol de Estados Unidos (EE.UU.) que en este proceso “representa la 'fuerza extraregional' que promueve u obstaculiza la integración" (Puig, 1981: 112).

Por otro lado, el segundo caso posee un marcado acento político y cultural por ser un instrumento para lograr autonomía, sobre la base de reconocer un mismo status y/o valores. La tendencia a la autonomía dentro del bloque exige, en lo externo, estrategias solidaristas con los integrantes del bloque que aspiran a lo mismo, así como con otros grupos y Estados que podrían ensanchar la base de los propios

\footnotetext{
${ }^{9}$ En su escrito de 1986 sostuvo que uno de los "defectos", además del unilateralismo y el economicismo interdependiente, de las propuestas de integración llevadas a cabo, era que se apuntó "a la integración "entre Estados" ..." (Puig, 1986: 42)

10 Como apuntó muy bien José Briceño Ruiz, a diferencia de los teóricos de la dependencia que criticaban la integración propuesta por CEPAL por considerarla "inviable", los autonomistas sostuvieron que "además de desarrollo industrial, se necesitaba promover políticas a favor de una mayor autonomía para lograr mayor viabilidad nacional y consolidar el propio desarrollo industrial." (Briceño, 2012: 54)
} 
recursos del país. (Puig, 1980, 208) Es decir, la integración no es cualquier instrumento; es el esencial para el logro de la autonomía: "(...) la integración solidaria se fundamenta en alianzas, vale decir, en uniones de Estados decididos a conseguir determinados objetivos sectoriales, pero que se fundamentan en valores compartidos, entre los que se descuella el de autonomía". (Puig, 1986, 59-60) Esto le permite a sus discípulos, como Luis Dallanegra Pedraza, incorporar la idea en la cual los Estados periféricos pueden definir una política exterior acorde a sus intereses, acumulándolo no solo de acuerdo a un patrón de suma cero, como creía Puig, sino también a partir de generar un "contrapoder" que supone generar "inmunidades" frente al poder dominante. (Dallanegra, 1998, 93-94)

La "Autonomía secesionista" "significa el desafío global. El país periférico corta el cordón umbilical que lo unía a la metrópoli”. Esta etapa no es recomendable, para el autor, ya que agota los recursos nacionales y puede derivar en una situación absolutamente contraria a la deseada. (Puig, 1984: I: 79-80)

La operatividad de los conceptos la podemos observar en sus análisis de la historia de la política exterior argentina donde constituyen una lógica "cíclica que no se desarrolla por etapas" sucesivas, como en la última posguerra cuando existió una puja entre los esquemas de dependencia racionalizada con EE.UU. y Autonomía heterodoxa. (Puig, 1984, I, 63)

El punto neural de la interpretación puiguiana está en el ámbito interno, ya que el Estado, no es un dato dado, como en las interpretaciones neoliberales y neoconservadoras, sino un objeto de una lucha entre fracciones autonomistas y aquellas a favor de la dependencia, que pujan entre sí por su control. Aunque, precisamente la inestabilidad generada por esta lucha, no aleja la capacidad de explicar la racionalidad del proceso, sino que es su fundamento. Dicho en sus propias palabras, se presenta: "(...) una correlación heurística que permite explicar con cierta coherencia los pretendidos vaivenes de la política externa argentina y, en todo caso, las razones que fundamentan su aproximación a, o su alejamiento, del respectivo margen potencial". (Puig, 1984, I: 93) Es decir, el comportamiento estructural de la política externa argentina está determinado por una disputa de carácter dialéctico entre esos dos modelos.

El punto extremo del proceso de autonominzación es la ruptura estratégica, decisión de las elites que agota las capacidades del Estado Nación ya que lo ponen ante objetivos que no puede cumplir, por lo cual no se presenta recomendable.

El cuarto criterio del régimen internacional es "la permeabilidad extrabloque", y estuvo reservado, en la visión de Puig, a los nuevos estados de África y Asia -los cuales pueden mantenerse al margen de los criterios y no ser forzados a algún alineamiento- pero ello no impide la disputa de las superpotencias por el dominio de esos espacios, lo que podría desestabilizar el régimen internacional. (Puig, 1984, I, 8799)

El último criterio obedece a la aplicación de "la prohibición del uso de la fuerza para los Estados medianos y pequeños" con algunas excepciones, aprovechando los resquicios abiertos por la contradicción entre las normas pragmáticas y "que en el 
Perspectivas Revista de Ciencias Sociales - ISSN 2525-1112|Año 3 No. 6 Julio-Diciembre 2018, pp. 221-242

fondo exceptúa a las superpotencias de la aplicación de la regla". (Puig, 1984, I, 8990)

\section{El régimen internacional puigiano en el banco de pruebas de la actualidad}

Para develar si el pensamiento puigiano sigue siendo útil como instrumento de política externa a través de operativizar los conceptos en el escenario actual, seguimos la propuesta esbozada por Antonio Niño de utilizar la historia del tiempo reciente como "banco de pruebas empíricos donde las teorías deben demostrar sus prestaciones y sus posibilidades (...)" (Niño, 2001, 149) Incluso, el propio Puig ha indicado en este sentido que: "(...) Los hechos deben imbricarse coherentemente en una teoría que les dé sentido, tanto desde el punto de vista de la captación fehaciente de los fenómenos de los cuales se aplica cuando de la posible transformación de dichos fenómenos por la adopción de políticas y estrategias concretas (...)". (Puig, 1980, 146) Es decir, nos proponemos seguir los hechos para comprobar la teoría y no al revés, como algunas de las nuevas escuelas del internacionalismo argentino.

\section{La posesión de armas de destrucción masiva}

Es el primero de los criterios establecidos por Puig, y se vincula más con una relación de subordinación en términos de un orden Norte-Sur que con el conflicto Este-Oeste, ya que ambas superpotencias se encargaban de impedir su proliferación en sus áreas de influencia y evitar que su poder se diluya. Esta preocupación por parte de los países dominantes continúa presente, como se observa, tanto en los enfoques teóricos como los de realistas estructurales (Krasner, 1989) o neoconservadores (Krauthammer, 1990), como así también en el despliegue de acciones tendientes a impedir el desarrollo nuclear de países periféricos (India, Pakistán, Irán, Corea del Norte, etc.), o reinterpretando los alcances del Tratado de No Proliferación Nuclear (TNP) para hacerlo más restrictivo.

Que la justificación de las políticas de desnuclearización para países periféricos haya sido el centro de autores como Carlos Escudé, no sorprende por su rechazo a cualquier instrumento de construcción de autonomía, aunque lo encubra en "la desmedida ambición de poder interestatal de las elites de algunos de sus Estados, [que] puede destruir al planeta". (Escudé, 1999, 12) En este marco deben entenderse la firma del tratado Tlatelolco y del TNP por parte de Argentina y Brasil, aunque sus gobiernos buscaron que ella no fuera percibida como como una concesión unilateral, sino "como el fruto de un acuerdo regional." (Busso, 1994, 53) Este hecho fue reconocido por el G8 ante la escalada armamentística que involucró a India y Pakistán en los años noventa, y fue resaltado por Escudé como un logro de la política exterior argentina de ese tiempo. (Escudé, 1999, 17)

Cabe decir que, si bien existieron protestas por parte de las superpotencias, se produjo cierta apertura del club nuclear (India y Pakistán), no así para otros donde se continúa presionando: el caso de Irán y Corea del Norte. Esta realidad, junto con el alejamiento de la esperanza de un mundo unipolar en el cual la teoría de Escudé tenía su espacio de comodidad, lo llevó a especular en la primera década del nuevo milenio y sostener que, en los últimos años, producto del "caos sistémico" se "han reducido 
Perspectivas Revista de Ciencias Sociales - ISSN 2525-1112|Año 3 No. 6 Julio-Diciembre 2018, pp. 221-242

los costos de las confrontaciones con la potencia hegemónica", lo que que tuvo como consecuencia que las "ecuaciones del 'realismo periférico' se ha(ya)n transformado". (Escudé, 2004: 19)

Esta reducción de la capacidad de sanción se debe según Escudé a que:

“(...) La capacidad de los EE.UU. para aplicar sanciones ha disminuido, porque está demasiado comprometido con sus guerras como para darse el lujo de hacerse más enemigos. Además, la gran potencia norteamericana ha demostrado no estar a la altura del papel de gendarme mundial que pretendió ejercer." (Escudé, 2007, 18)

El dato evidente fue la sobreevaluación inicial por parte de Escudé de la capacidad de disciplinamiento de las grandes potencias y no haber puesto atención en los márgenes de maniobra, como recomendaba Puig.

\section{La división en bloque y su impermeabilidad}

La emergencia de la guerra fría tuvo dos características: era bipolar, lo que producía alianzas rígidas y permitía la impermeabilidad interbloque. Este es el punto crítico, ya que posteriormente no emergió un actor "dominante" o un grupo de ellos que ejerza "una función hegemónica" para dirigir el sistema de Estados en la dirección deseada, ello percibido como la protección del bienestar general. (Arrighi, 1999, 44)

El fin de la Guerra Fría no supuso la imposición de un orden mundial que reemplazara al bipolar, ya que existió una tensión entre la búsqueda norteamericana por lograr hegemonía y formas de oposición a ella, como expresión de cierto proceso de autonomización por parte de algunos Estados, a pesar de no existir bloques a los cuales referirse. Ingenuamente se supuso que con ella, al desaparecer uno de los polos, emergería un orden unipolar, pero ésta presunción desconoció los problemas que atravesaban los EE.UU., como lo indicaron Giovanni Arrighi (1999), Paul Kennedy (1990), o Eric Hobsbawn (1995). El centro del poder mundial en los años noventa, según Ignacio Ramonet, lo constituyeron Europa Occidental, América del Norte y Japón, siendo éstos "una tríada de poder" que concentró: “(...) los más grandes excedentes financieros, los principales conglomerados industriales y lo esencial en innovación tecnológica. Esta tríada domina el mundo como ningún imperio lo hizo antes". (Ramonet, 1997, 21)

Esa estructura particular determinó una forma de funcionamiento internacional, desde la segunda presidencia de Reagan. Así:

“(...) Durante la segunda administración Reagan (...) FMl fue ya dotado del poder necesario para que actuara como Ministerio de las Finanzas Mundiales. Bajo la administración Bush se reforzó esa tendencia y, lo que resulta de mayor importancia, el Consejo de Seguridad de Naciones Unidas fue dotado del poder necesario para que actuase como Ministerio de Policía Mundial. Y bajo ambas 
administraciones, las reuniones regulares del Grupo de los Siete lograron que ese organismo se asemejase cada vez más al consejo de administración de los asuntos colectivos de la burguesía mundial”. (Arrighi, 1999, 398)

Esta forma de consorcio, a la que se sumó la Rusia de Yeltsin en los noventa, no estuvo exenta de disputas que llevaron a algún sector de Washington a reclamar un diseño unipolar. Desde mediados de los noventa, Rusia, China, Francia y Alemania tomaron acciones para limitar el poder norteamericano, pero luego del desarrollo de la guerra contra el terrorismo, París y Berlín se aproximaron a Washington, mientras Moscú y Beijing institucionalizaron primero el Grupo Shanghái y luego los BRICS, comenzando a delinear un polo alternativo. En el nuevo milenio esta indefinición continuó a pesar del intento de imponer el Proyecto para un Nuevo Siglo Americano por parte de la administración de George W. Bush (hijo), que según Arrighi, buscó "establecer el primer imperio auténticamente global de la historia." (Arrighi, 2007, 15) Una muestra de ello fue su incapacidad para atender varios frentes simultáneos: sólo se concentró en el Oriente Medio, cuestión que permitió generar márgenes de maniobra en otras áreas, como en América Latina. ${ }^{11}$

Asimismo, ese intento por recuperar la hegemonía norteamericana se encontró con el crecimiento de China desde 1990. El desplazamiento de la centralidad de Japón por China en el desarrollo del Lejano Oriente y sus Tigres, no fue inocuo para Washington, ya que Beijing no es dependiente ni militar ni políticamente de EE.UU.. (Arrighi, 2007, 16) E incluso, "el resultado de la debacle iraquí puede muy bien marcar el surgimiento de China como auténtico vencedor de la guerra estadounidense contra el Terror." (Arrighi, 2007, 17) ${ }^{12}$

El ascenso de las nuevas fuerzas se evidenció con el fracaso de Washington para imponer su estrategia en la OMC consistente la agenda llamada OMC Plus (inversiones, patentes, competencia, etc.).

Desde la asunción de Obama, EE.UU. neutralizó las tendencias policéntricas e intentó volver a mantenerse en el centro del esquema de poder mundial, ya que tenía una relación tensa con Europa, América Latina poseía amplios márgenes de maniobra y las guerras en Irak y Afganistán drenaban sus recursos e incrementaba su nivel de endeudamiento. Obama llevó adelante una drástica reducción de su presencia militar en aquellos escenarios de Oriente, gracias a un retiro parcial de tropas, pero esto generó otros tipos de problemas que produjeron un vacío de poder y el recrudecimiento de la violencia en esas áreas, si bien logrando en esta oportunidad un mayor concurso de los europeos occidentales. Además, estimuló a los países más próximos en la región (Chile, Colombia, México y Perú) a formar la Alianza del Pacífico, lo que le permitió a Washington presentar una alternativa a la hegemonía brasileña

\footnotetext{
${ }^{11}$ Este escenario fue el que permitió a la Argentina volver a un modelo autonómico en clave puigiana, a pesar del virtual colapso del Estado, primero, y luego, durante el segundo mandato de Cristina Fernández de Kirchner, hacia otro más recostado en el bando de los emergentes.

12 Henry Kissinger hizo una evaluación similar (2012)
} 
que giró en torno de la UNASUR y a la bolivariana, que hizo lo propio con el ALBA. (Menezes y Goularth Menezes, 2016)

En este marco, la promoción por parte de Washington de acuerdos, como el TTIP con la Unión Europea, y el TPP o transpacífico, indican cambios en sus estrategias de negociación multilateral con el abandono de la OMC, como foro de discusión y formador de reglas y en donde China y las economías emergentes habían ganado espacios significativos y habían logrado bloquear iniciativas en torno a los temas de la ya mencionada OMC Plus.

En otro plano, en el caso de China, tras la crisis de 2008, dejó de ser exclusivamente un proveedor de manufacturas a nivel global, receptor de inversiones y soporte financiero del déficit norteamericano, y se volcó también hacia el mercado interno, diversificando sus utilidades y promocionando inversiones en Asia, África y América Latina para disminuir su vulnerabilidad externa y garantizar su provisión de alimentos, materias primas y energía, y rompiendo las bases de "chimérica". (Ferguson, 2005) $)^{13}$

Beijing ha utilizado diversos mecanismos multilaterales para afianzar su poder político y económico como con la Organización de Cooperación de Shanghái, los BRICS, la Franja Económica de la Ruta de la Seda y su ruta marítima (con los países de ASEAN), pero también como se observó en 2015, no dudo en buscar un dialogo bilateral y casi como pares con Washington.

Dentro de los medios multilaterales queremos rescatar la Asociación Económica Integral Regional, conocida por sus siglas en inglés RCEP (2012), acuerdo que propone la creación de una zona de libre comercio para 16 países (formado por los miembros del ASEAN y quienes tienen tratados de libre comercio con esa organización) y abarcando a 3.400 millones de personas.

Esta nueva posición de Beijing, sumada a su asunción como un líder global ${ }^{14}$, llevaron a Washington a impulsar aquellos acuerdos (TPP, TTIP y TISA) para generar reglas acordes a sus intereses y creando, según Matthew Cooper de Newsweek, un efecto de "pinzas de cangrejo" sobre China. (Cooper en Montesa y Azcárate, 2015) La importancia que ellos tuvieron para Washington quedó claramente explicitada cuando Obama en la conferencia de prensa conjunta con el Primer Ministro de Singapur, Lee Hsien Loovy en agosto de 2016, señaló que EE.UU. no puede separar su "seguridad" de sus intereses económicos contenidos en este tipo de tratados, y

\footnotetext{
${ }^{13}$ Es un neologismo inventado por Naill Ferguson (2008) quien buscó explicar la simbiosis existente entre las economías de China y Norteamérica, donde la primera aporta manufacturas baratas y con sus excedentes comerciales compra bonos del tesoro para financiar el déficit de Washington y así sostener la deuda que genera aquella.

${ }^{14}$ Como ha explicado Moncada Durruti (2011) Beijing se fue alejando del siglo de humillaciones iniciada en la Guerra del Opio y afirmando un rol más preponderante en el escenario internacional donde las ambigüedades entre el pragmatismo de los "28 caracteres de Deng Xiaoping" y el principismo de los "Cincos Principios de la Coexistencia Pacífica, con una preponderancia de éstos últimos en conflicto con la hegemonía neoliberal actual. Esto ha sido confirmado por el "Documento sobre la política de China hacia América Latina y el Caribe" de noviembre de 2016.
} 
que de ellos depende quien manejará el comercio global, si ellos o Beijing. (DW, 2016) $)^{15}$

La profundidad del cambio anunciado en campaña por Donald Trump estará vinculada a cómo su programa America First (Norteamérica primero) sea implementado, y cómo afectará al modelo vigente en EE.UU. desde los años de Reagan, no sólo en su agenda interna sino también externa.

Si bien las medidas anunciadas durante la campaña atentan contra el orden neoliberal vigente, la nominación de gente vinculada a Goldman Sach (Mars, 2017) y a la "Heritage Foundation", hacen dudar sobre los alcances del cambio, sobre todo en materia financiera. ${ }^{16}$

En el plano externo su rasgo basal será de un fuerte unipolarismo y puede interpretarse como una vuelta de tuerca del programa para el "Nuevo Siglo Americano" de comienzos del milenio, aunque con una situación más compleja para Washington. Asimismo, será complementada por el aislacionismo, lo que no quiere decir que haya menos intervencionismo, sino que convertirá a EE.UU. en un gendarme de tiempo parcial y con un mayor uso de su capacidad individual punitiva. Como consecuencia de ello existirá cierta marginación de organismos multilaterales como las Naciones Unidas, o incluso la OTAN, donde sus socios quedarán librados a su suerte. $Y$ desde lo económico una retracción en la promoción del libre cambio, por una propuesta más proteccionista, constituiría un giro brusco en la política exterior de Washington. Ello se evidencia en la denuncia del TPP ${ }^{17}$, resultando un duro golpe a la gobernanza global, dada la apuesta a más bilateralismo que multilateralismo.

Cabe decir que es extraña esta jugada ya que con la concreción del TTIP se lograría satelizar definitivamente a Europa, golpeada por la crisis del euro, y plegada activamente a su estrategia de seguridad, como lo mostraron las intervenciones en Libia y Siria. Aunque el objetivo, convertir al Viejo Continente en un actor secundario, no es abandonado, la diferencia está entre un liderazgo por cooptación y otro por imposición, obligando a hacerse cargo de los gastos de su defensa, más allá de que la aproximación de Trump a Putin se haga efectiva.

La estrategia de las "pinzas de cangrejo" ensayada por los demócratas, parece quedar abandonada por la promoción de aranceles aduaneros, cuestión que desatará guerras comerciales y dará otra estocada grave a la ya herida OMC.

Ante la defección de EE.UU. del TPP, el presidente chino, XI Jinping propuso al RCEP en la conferencia de APEC de Lima de noviembre de 2016, como instrumento para la promoción del libre cambio en el área del Pacífico, aunque éste "no considera a los países latinoamericanos que están en la APEC como México [único de los tres sin tratado de libre comercio con Beijing], Chile y Perú." Fue sintomático que en la Declaración final de ese foro se sostuvo: "Animamos a que todos los compromisos

\footnotetext{
${ }^{15}$ Estos acuerdos y la situación emergente de ella, generaron temores de quedar fuera de las corrientes de inversiones en los grupos dominantes de la periferia.

16 Clarín, 20/1/2017, disponible en: http://www.clarin.com/mundo/equipo-sombras-donaldtrump_0_Sk1OWKRUI.html, consultado el 20/2/2017

${ }^{17}$ Obama ya lo había hecho el TTIP.
} 
regionales, incluyendo el TPP y el RCEP, permanezcan abiertos, transparentes e inclusivos y se atraigan entre si". 18

En este contexto, se evidencia que la falta de definición del tipo de modelo de sistema internacional, que osciló entre la búsqueda del unipolarismo, pasando por un momento multipolar, y que solo recientemente aparecería delinearse uno bipolar, afecta al concepto de impermeabilidad extra bloque.

\section{La autonomización}

El rol de este criterio es la gran pregunta para la cuestión que nos ocupa en el presente trabajo, el cual no está en la constatación de las mudanzas del mundo, sino en cuanto afecta ésta a la funcionalidad de la autonomización. Este proceso posee ajustes permanentes ya que la elite autonomista puede revisar su actitud disminuyendo su margen potencial de decisión, o puede ser desplazada por una contra-elite dependentista; o bien que aquella se encuentre acorralada y cambie a un nuevo bloque; cuestión que puede llevar a la potencia dominante a intervenir militarmente. (Puig, 1986, 62-63)

Más allá de ello, los cambios del sistema internacional no afectaron a la autonomía, ya que en los años noventa el margen de maniobra fue más reducido, pero no desapareció, como lo indicó Helio Jaguaribe, cuando reclamaba una estrategia conjunta de Argentina, Brasil y Venezuela frente a la constitución de una era Imperial Americana y; se potencia en un marco multipolar actual, al ser muchos actores los que compiten por la hegemonía, ampliando las opciones de inserción. (Jaguaribe, 2003) Eso explica por qué los discípulos de Puig, como en el caso de Raúl Bernal Meza, han sostenido la vigencia del pensamiento puigiano. En este sentido, para ello se han asentado en dos cuestiones: que los lazos de dependencia se han modificado en la forma, pero no en el fondo, y que esto incluso se profundizó; y, en segundo lugar, que la integración sigue siendo la opción más óptima frente a la alternativa individual; salvo para países que tienen capacidades y potencialidades de gran crecimiento en sus atributos nacionales de poder, como es, en nuestra región, el caso del Brasil. (Bernal Meza, 2013, 46)

Rescatando un aspecto nodal del pensamiento puigiano, cabe decir que para que exista proyecto autonómico es necesario que existan elites funcionales a tales objetivos. (Bernal Meza, 2013, 48)

En efecto, además de estos dos criterios del pensamiento puigiano (integración solidaria y elites funcionales) su actualidad está complementada por otros como la no aceptación de imposición de acciones en nombre del bloque y la necesidad de aceptar algunos supuestos básicos en torno a la seguridad, la alimentación y la energía. (Bernal Meza, 2013, 54-55)

En el caso de la lectura de Miryam Colacrai, apuntó a una redefinición de la autonomía, ya que sus postulaciones "no son un mero recuerdo histórico, puesto que gran parte de las discusiones que allí se planteaban no han sido saldadas todavía", incorporando al concepto puigiano, "la dimensión regional como parte sustancial de ella y no como mera agregación." (Colacrai, 2009: 35 y 45) Es claro que esta

18 Disponible en: https://chinaenamericalatina.wordpress.com/2016/11/24/china-promueve-laasociacion-economica-integral-regional-rcep-como-alternativa-al-ttp/, consultado el 20/02/2017 
interpretación fue posible por la crisis del Estado-Nación, dónde no pueden realizar sus intereses en solitario, como lo ha apuntado también Helio Jaguaribe. (2006)

El enfrentamiento entre los modelos autonomistas heterodoxos y los dependentistas racionalizados, que caracterizó a la guerra fría, se vio reforzado por los aportes de Guillermo Figari, quien considera que en la Argentina democrática se produjo una "maduración conceptual" de nuestra política exterior. Esta se orientó en dos cuestiones fundamentales: 1) que no puede existir una oposición visceral, ni un alineamiento acrítico hacia los EE.UU.; y, 2) el impulso de una política cooperativa hacia América Latina, con eje en Brasil. (Figari, 1993: 221)

La primera cuestión, habilitó la posibilidad de tener una política autonomista heterodoxa y llevar una orientación madura con EE.UU. Es lo que Figari denominó posautonomismo, un punto de equilibrio entre los modelos occidentalista y latinoamericanistas que confrontaron durante gran parte de la Guerra Fría. (Figari, 1993) Pero esta nueva orientación no sería completa sin tener en cuenta la nueva disposición cooperativa hacia la región con acento en Brasil, como se observa incluso en los gobiernos con inclinación dependentista (Menem, De la Rúa y Macri), cosa que en el pasado no ocurría, ya que las políticas occidentalistas presumían del aislamiento o la confrontación regional.

Si existe un elemento de continuidad en la política exterior argentina desde 1983, este fue la estructura triangular que puso al tope de nuestra agenda a Washington y Brasilia -utilizándolos como contrapesos-, en un marco predominantemente cooperativo, dejando a un lado las oscilaciones del pasado.

De todos modos, por otro lado, la irrupción de China al promediar la primera década del nuevo milenio, ha obligado a pensar en un escenario distinto al triangular, como así también en cuales serían los lineamientos de un modelo autonomista de carácter heterodoxo que se ha visto reflejado en la utilización más próxima al denominado "regional" de Mario Rapoport. (Rapoport y Miguez, 2014) periférico:

Como señaló Luis Dallanegra Pedraza, la política exterior de un Estado

“(...) no puede ser el instrumento de subordinación, sino de búsqueda de mejores condiciones. Tener conciencia de que, dadas las características del sistema internacional y su estructura, la ubicación y posibilidades de la gran mayoría de los Estados revela su debilidad, debe llevarnos a buscar caminos 'prudentes' para modificar esa situación y condición en beneficio propio, no a la resignación, por el hecho de carecer de poder". (Dallanegra, 2009: 4-5)

E incluso, su contracara, un modelo de inserción dependiente, puede ser puntualizado como lo hizo el mismo autor:

1) Inserción racional dependiente de la primera potencia de rango mundial.

2) Indiferencia y/o oposición a toda potencia alternativa a la principal potencia de rango mundial con la que se mantienen vínculos de dependencia. 
3) Asilamiento -salvo excepciones- en relación con la región latinoamericana y otros países de la periferia.

4) Indiferencia en relación con el territorio que no constituya la pampa húmeda y el puerto de Buenos Aires y debilidad en la política territorial (Dallanegra, 2009: 152)

Si bien tres de las cuatro características habían sido señaladas por Juan Carlos Puig para la dependencia racionalizada, el segundo punto ("indiferencia u oposición a toda potencia alternativa"), vino a sanear uno de las críticas más sólidas al planteo puigiano, su focalización excesiva en EE.UU. Y para el cado de la tercera, existe un rol más activo, no para garantizar la diversificación, sino la subordinación.

\section{La permeabilidad extrabloque}

El cuarto criterio, de permeabilidad extrabloque, estuvo reservado, en la visión de Puig, a la disputa de las superpotencias por el dominio de los países descolonizados y cómo ello podría desestabilizar a aquel régimen internacional. La existencia de él se puede percibir en el abandono por parte de Beijing de la política de triangulación en el área latinoamericana que había caracterizado a su política hacia la región hasta los primeros años del nuevo milenio, en la cual Washington tendría el rol de una potencia global y Beijing el de una regional y América Latina el de una región subordinada. (Tokatlián, 2008: 88) La asunción de Beijing como país importante y la creciente preocupación norteamericana por ello resulta un dato significativo de este criterio y del proceso.

\section{La prohibición del uso de la fuerza para las potencias medianas y pequeñas.}

En este caso no ha habido cambios en cuanto al uso selectivo del criterio, pero si una ampliación, ya que el uso de la fuerza no se refiere solamente al escenario externo sino también interno, como se observa en la aplicación del derecho a proteger.

La sucesión de intervenciones en el Irak de Hussein, la Yugoslavia de Milosevic, en el Afganistán del talibán, en la Libia de Gadafi, o en la Siria de Al Asad, son buenos ejemplos de ello. Tomemos el caso de Libia y como señaló Tzvetan Todorov:

“(...) las democracias occidentales: consideran que su superioridad militar les atribuye el derecho, o incluso el deber, de gestionar los asuntos de todo el mundo (excepción hecha de los otros miembros permanentes del Consejo de Seguridad y de sus protegidos) imponiendo a los países mal clasificados los valores que ellas juzgan superiores y, en la práctica, los Gobiernos que estiman aptos para conducir la política apropiada. Cual variante moderna de la fórmula de Kipling, ya no se trata de 'la carga del hombre blanco', sino de la del homo democraticus. La causa humanitaria (impedir el baño de sangre) resulta ser una especie de caballo de Troya, un buen pretexto para intervenir militarmente y controlar la orientación política de los Estados rebeldes. Conviene dejar constancia de que todos los esfuerzos desplegados por las potencias occidentales 
para 'moralizar' las guerras no conciernen hasta el momento más que al embalaje mediático que se hace de todo ello." (Todorov 2011,17)

Esta hemiplejia con respecto a uso y evaluación de la violencia, no es arbitraria, sino que busca el disciplinamiento de las diversas elites periféricas que pueden representar un problema para la búsqueda de su hegemonía.

\section{Conclusión}

La guerra fría encerró dos tipos de conflictos: el Este-Oeste y el Norte-Sur. El primero, termina con el fin de la URSS, pero el segundo no y como la teoría puigiana se apoya en ambos elementos, pero sobre todo en el último, el más importante para un país periférico, le otorga continuidad a ese pensamiento.

Frente al carácter estatocéntrico de las relaciones internacionales, resultó que a lo largo de la segunda mitad del siglo XX han aparecido otros tipos de actores en el escenario internacional, como señaló Puig, pero esta situación dista de hacer desaparecer al Estado-Nación como uno relevante.

En relación con el primer criterio, se ha mostrado esquivo ya que se aceptó la incorporación de algunos miembros al club (p.e. India y Pakistán) pero se ha mostrado particularmente tenaz en otros casos (Irán y Corea del Norte). El dato evidente fue la sobreevaluación inicial de la capacidad de disciplinamiento de las grandes potencias por parte de Escudé y lo acertado de la propuesta de Puig.

La falta de definición del tipo de modelo de sistema internacional que osciló entre la búsqueda del unipolarismo, pasando por un momento multipolar, y que solo recientemente aparecería delinearse uno bipolar afecta al concepto de impermeabilidad extra bloque.

El tercer criterio, y a pesar de los diversos escenarios, la autonomización se ha mostrado efectiva para explicar la evolución de la política externa argentina donde el cariz de los márgenes de maniobra son la espina dorsal del proceso de inserción internacional.

El cuarto criterio, ganó relevancia y desplazó al segundo, ya que los territorios de América Latina, África y Asia están siendo objeto de una particular disputa en los años recientes que permiten a aquellos países que hacen una lectura correcta, aprovechar los márgenes de maniobra que la falta de estabilización del sistema y la disputa inherente a ella generan.

El quinto criterio, sigue siendo un criterio disciplinador, pero la disputa entre los grandes jugadores ha generado situaciones equivocas al respecto.

En efecto, a partir de ellos, resultaba claro que el sistema bipolar era más estable a la luz de otros tipos de escenario, pero su desaparición creó otras formas de anarquía y de márgenes de maniobra. La continuidad y mutación de algunos criterios puigianos en función de cómo la asimetría se moldea en el sistema internacional resulta un dato objetivo para la promoción de los márgenes de maniobra, sólo falta la voluntad de las elites para su logro. 
Perspectivas Revista de Ciencias Sociales - ISSN 2525-1112|Año 3 No. 6 Julio-Diciembre 2018, pp. 221-242

\section{Bibliografía}

Arrighi, Giovanni. 1999. El largo siglo XX. Madrid, Akal, 1999.

Arrighi, Giovanni. 2007. Adam Smith en Pekin. Orígenes y fundamentos del Siglo XXI. Madrid, Akal.

Bernal Meza, Raúl. 2013 "Heterodox Autonomy Doctrine: realism and purposes and its relevance" en Revista Brasileña de Política. Internacional, 56 (2): 45-62.

Bernal-Meza, Raúl. 2016. "Contemporary Latin American thinking on International Relations: theoretical, conceptual and methodological contributions" en Rev. Bras. Polít. Int., 59(1): e005, 2016, 1-32

Bologna, Alfredo Bruno. 1987. Teorías y propuestas de relaciones internacionales para los países del Sur. Rosario, CERIR, Serie Documentos de Trabajo № 1.

Briceño Ruiz, José. 2012. "Autonomía y Desarrollo e el pensamiento integracionista latinoamericano" en Briceño Ruiz, José, Rivarola Puntigliano, Andrés y Casas Gragea, Ángel M. Integración latinoamericana y caribeña. Política y economía. Madrid, Fondo de Cultura, pp. 27-58.

Busso, Anabella. "La relación bilateral con los EE.UU. en el Gobierno de Menem" en: Relaciones Internacionales. La Plata, año 4, № 6, Mayo de 1994, 33-55.

Cervo, Amado Luiz. 2003. "Política exterior e relações internacionais do Brasil: enfoque paradigmático" en Revista. Brasileña de Política Internacional. 46 (2): 5-25.

Colacrai, Myriam. 2009. "Los aportes de la Teoría de la Autonomía, genuina contribución sudamericana ¿la autonomía es hoy una categoría en desuso o se enfrenta al desafío de una renovación en un contexto interdependiente y más complejo?" LECHINI, Gladys, KLAGSBRUNN, Víctor e Gonçalves, Williams (Org.) Argentina e Brasil: vecendo os presconceitos. As variadas arestas de uma concepción estratégica. Río de Janeiro-Rosario, Revan, pp. 33-49.

Dallanegra Pedraza, Luis. 1998. El orden mundial del siglo XXI. Buenos Aires, Ediciones de la Universidad.

Dallanegra Pedraza, Luis. 2009. Realismo-Sistémico-Estructural: La Política Exterior como «Construcción» de Poder, Córdoba, Argentina, Edición del Autor

Deutsche Welle. 2016. "Obama reafirma su compromiso con el acuerdo comercial TPP", 3 de agosto de 2016, disponible en: http://www.dw.com/es/obama-reafirma-sucompromiso-con-el-acuerdo-comercial-tpp/a-19445157, consultado el 20/8/16.

Escudé, Carlos. 1999. Estado del mundo. Las nuevas reglas de la política internacional vistas desde el cono sur. Buenos Aires, Ariel.

Escudé, Carlos.2004. "A río revuelto. Autonomía periférica en un contexto de desorden global" Agenda Internacional. Visión desde el sur (I) 1:16-27.

Escudé, Carlos. 2007. "Occidentales con disimulo", en La Nación, 17 de octubre de 2007, 18.Escudé, Carlos. 2012. "El protectorado argentino y su indefensión actual: un análisis desde el realismo periférico", presentado en la Conferencia FLACSO-ISA "Poderes globales y regionales en un mundo en cambio" de Buenos Aires, julio de 2013. 
Perspectivas Revista de Ciencias Sociales - ISSN 2525-1112|Año 3 No. 6 Julio-Diciembre 2018, pp. 221-242

Ferguson, Naill. 2005. Coloso: Auge y decadencia del imperio americano. Madrid, Debate.

Figari, Guillermo. 1993. Pasado, presente y futuro de la política exterior argentina. Buenos Aires, Biblos.

Halliday, Fred 2002. Las relaciones internacionales en un mundo en transformación. Madrid, Catarata.

Hobsbawm, Eric. 1995. El Siglo XX. Barcelona, Crítica.

Jaguaribe, Helio. 1979. "Autonomía periférica y hegemonía céntrica." en: Estudios Internacionales. Santiago de Chile, № 49, Abril-junio 1979, 91-130.

Jaguaribe, Helio. 2006. "Argentina y Brasil ante el Siglo XXI" en Num, Jose y Grimson, Alejandro, Convivencia y buen gobierno. Nación, nacionalismo y democracia en América Latina, Buenos Ares, Edhasa], 203-210.

Jaguaribe, Helio (2009) "Brasil-Argentina, a indespensavel alianca" Lechini, Gladys, Klagsbrunn, Víctor e Goncalves, Williams (Org.) Argentina e Brasil: vecendo os presconceitos. As variadas arestas de uma concepción estratégica. Río de JaneiroRosario, Revan, pp.11-17

Krasner, Stephen D. 1989. Conflicto estructural. El Tercer Mundo contra el liberalismo global. Buenos Aires, Grupo Editor Latinoamericano.

Krauthammer, Charles. 1990. "The Unipolar Moment" en. Foreign Affairs, Vol. 70, Nº 1, 23-33.

Kennedy, Paul. 1990. Auge y caída de las grandes potencias. Madrid, Plaza y Janés. Kissinger Henry. 2012. China, Buenos Aires, Debate.

Laviña, Felix y Baldomir, Horacio. 1983. Manual de Política Internacional. Buenos Aires, Depalma.

Mars, Amanda. 2017."Goldman Sachs, el banco que gobierna el mundo" en El País Negocios, Madrid, 5 de febrero de 2017, 2-4.

Menezes Klemi, Albene Miriam y Goulart Menezes, Roberto. 2016. "Brasil e Mercusul: rumos da integração na lógica do neodesenvolvimentismo (2003-2014)" en Caderno Centro de Recursos Humanos, V. 29, Salvador, UFB, Septiembre, 135-150.

Moncada Durruti, Mariola. 2011. "Visión del mundo exterior de las cuatro generaciones de líderes políticos de la República Popular de China: evolución histórica y conceptual", en Documentos CIDOB- Asia 27, Barcelona, Junio 2011, disponible en: http://www.cidob.org/en/publicacions/documentos_cidob/asia/vision_del_mundo_ext erior_de_las_cuatro_generaciones_de_lideres_politicos_de_la_republica_popular_chi na_evolucion_historica_y_conceptual, consultado el 26/06/2015.

Montesa, Ferrán y Azcárate, Blanca. 2015. "Una Otan de la economía" en Le Monde Diplomatique en español, $\mathrm{N}^{\circ}$ 240, Madrid, octubre de 2015, disponible en: www.mondediplomatique.es/?url=articulo/0000856412872168186811102294251000 /?articulo=763f1dd55fb741028da9626d903f5403, consultado el 11/7/2016.

Niño, Antonio. "Historia y Teoría en el estudios de las Relaciones Internacionales" en Colacrai, Miryan, Relaciones Internacionales. Viejos temas, nuevos debates. Rosario, CERIR, 2001, 135-197. 
Perspectivas Revista de Ciencias Sociales - ISSN 2525-1112|Año 3 No. 6 Julio-Diciembre 2018, pp. 221-242

Pontes Nogueira, Joao e Messari, Nizar. Teoria das Relações Internacionais. Correntes e Debates. Rio de Janeiro, Elsevier, 2006.

Puig, Juan Carlos. 1970. "Discurso de Señor Profesor Dr..., Presidente del Primer Seminario Nacional de Profesores e Investigadores de Derecho Internacional Público" en Asociación Argentina de Derecho Internacional. La enseñanza y la investigación en la materia. Córdoba. Instituto interamericano de Estudios Jurídicos Internacionales, 31-34

Puig, Juan Carlos. 1978. "Derecho internacional americano, nacionalismo latinoamericano y régimen internacional." En: Mundo Nuevo Revista de Estudios Latinoamericanos. Caracas, Universidad Simón Bolívar, Instituto de Altos Estudios de América Latina, №1, julio-septiembre de 1978, pp.83-109

Puig, Juan Carlos. 1980. Doctrinas internacionales y Autonomía latinoamericana, Caracas, Universidad Simón Bolívar, Instituto de Altos Estudios de América Latina. Puig, Juan Carlos. 1981. "Nacionalidad, integración y autonomización." En: Mundo Nuevo Revista de Estudios Latinoamericanos. Caracas, Universidad Simón Bolívar, Instituto de Altos Estudios de América Latina, N¹1-12, enero-julio de 1981, pp.110117

Puig, Juan Carlos. 1983. "Prologo" en Laviña, Felix y Baldomir, Horacio. Manual de Política Internacional. Buenos Aires, Depalma, "VII-XIII.

Puig, Juan Carlos. 1984. América Latina: políticas exteriores comparadas. Buenos Aires, Grupo Editor Latinoamericano.

Puig, Juan Carlos. 1986 "Integración y Autonomía en América Latina en las postrimerías siglo XX" en: Integración Latinoamericana, t.11, № 109, Buenos Aires Instituto de Integración Latinoamericana, 40 a 62.

Puig, Juan Carlos. 1987. "Integración y Autonomía en América Latina en las postrimerías siglo XX" En: Integración Latinoamericana y Régimen Internacional. Caracas, Universidad Simón Bolívar, Instituto de Altos Estudios de América Latina.

Puig, Juan Carlos. 1994. "Integración y Autonomía a propósito de la Reunión del Foro Latinoamericano de Caracas" en Estudios de Derecho Internacional. Compilación de Delia C. de Puig y Ana Carrillo G. Caracas, Universidad Simón Bolívar, Instituto de Altos Estudios de América Latina, Fundación Bicentenario de Simón Bolívar, pp. 4567

Ramonet, Ignacio. 1997. Geopolitique du Chaos. París, Galileé.

Rapoport, Mario. y Miguez María Cecilia. 2014. "Desafíos y ejes para una inserción internacional autónoma de Argentina y América del Sur en el escenario mundial" en Briceño, José y Simonoff, Alejandro. Integración y cooperación regional en América Latina. Una relectura a partir de la teoría de la autonomía. Buenos Aires, Biblos. 143161.

Russell, Roberto y Tokatlián, Juan Gabriel. 2010. Autonomía y neutralidad en la globalización. Una readaptación contemporánea. Buenos Aires, Capital Intelectual. Salomón, Mónica. 2002. "La Teoría de las Relaciones Internacionales en los albores del Siglo XXI. Dialogo, disidencia y aproximaciones" en Revista Electrónica de Estudios Internacionales, N. ${ }^{\circ}$ 4, Asociación Española de Profesores de Derecho Internacional y Relaciones Internacionales. 
Simonoff, Alejandro. 2007. Los dilemas de la autonomía: La política exterior de Arturo Illia (1963-1966). Buenos Aires, Grupo Editor Latinoamericano.

Simonoff, Alejandro. 2009. "Apuntes sobre los conflictos de la posguerra fría" en: Revista de Ciencia Política. El Príncipe, La Plata, Año 3, № 2, Agosto-Noviembre de 2009, 15-38.

Simonoff, Alejandro. 2012. Teorías en movimiento. Rosario, Prohistoria.

Todorov, Tzvetan. 2011. "La guerra en Libia tres meses después” en El País, 8 de Julio de 2011, 17

Tokatlián, Juan Gabriel. 2008. "Una mirada desde América Latina”, en Paz, G. y Roett, R. La presencia China en el hemisferio occidental: consecuencias para América Latina y EE.UU.. Buenos Aires, Libros del Zorzal, pp. 77-116.

Tomas, Aurelio. 2016. "Mientras gira hacia Occidente, Macri congela los proyectos rusos y chinos" en Perfil, 23 de enero de 2016, disponible en: http://www.perfil.com/politica/Mientras-gira-hacia-Occidente-Macri-congela-losproyectos-rusos-y-chinos-20160123-0021.html, consultado el 9 de marzo de 2016. Waltz, Stephen. 1988. Teoría de la Política Internacional. Buenos Aires, Grupo Editor Latinoamericano. 